\title{
Urine Estrogen Profiles in European Countries with High or Low Breast Cancer Rates*
}

\author{
B. MACMAHON,$\uparrow$ A. P. ANDERSEN + J. BROWN $\S$ P. COLE,$\uparrow$ F. DEWAARD \\ T. KAURANIEMI, B. RAVHINAR, ${ }^{* *}$ N. STORMBY, $\dagger$ D. TRICHOPOULOS ++ \\ and $\mathrm{K}$. WESTLUND\&
}

$\dagger$ Department of Epidemiology, Harvard School of Public Health, 677 Huntington Avenue, Boston, MA 02115, U.S.A.; + Department of Oncology and Radiotherapy (Radium Center), Municipal Hospital, University of Aarhus, Denmark; $\$$ Department of Obstetrics and Gynaecology, University of Melbourne, Victoria, Australia; ||Institute of Social Medicine, University of Utrecht, Netherlands; Tancer Detection Clinic of the Finnish Cancer Society, Helsinki, Finland; **Institute of Oncology, Medical Faculty, University of Ljubljana, Yugoslavia; $\dagger \dagger$ Cytodiagnostic Department, Malmo General Hospital, University of Lund, Malmö, Sweden; $+_{++}^{+}$Department of Hygiene and Epidemiologr', Ciniversity of Athens, Greece; $\S$ Institute of Community Medicine, University of Troms $\$$, Norway

\begin{abstract}
Urine estrogens of women in two age groups, 15-18 and 30-39, were measured in four northern European countries where breast cancer rates are high, two southern European countries where they are low, and in Finland, a northern country where incidence rates are comparable to those of the southern countries and mortality rates are intermediate. The estriol ratio (the ratio of the concentration of estriol to the sum of those of estrone and estradiol) was lower in the high-risk countries than in the low-risk areas in both age-groups and in both the follicular and luteal phases of the menstrual cycle. In two of the four comparisons the difference was statistically significant. This provides modest support to the hypothesis that a population's breast cancer risk is inversely related to the estriol ratios of its young women. However, the data from Finland are not consistent with this hypothesis, the Finnish women having lower mean estriol ratios than the women in the high-risk areas. The pregnanediol levels of the young Finnish women were also unusually low, suggesting a high frequency of anozulatory menstrual cycles.
\end{abstract}

\section{INTRODUCTION}

The INCIDENCE of breast cancer varies appreciably among European countries, although the variability is less than that which is seen world-wide. Thus, the highest and lowest recorded national incidence rates of this disease in Europe differ by two-fold while the highest rates in Europe and North America differ from those of some Asian and African countries by a factor of five. Comparisons of the urine estrogen profiles of young North American and Asian women showed an inverse correlation between a population's breast cancer risk and the 'estriol ratio'- the amount of estriol (E3) excreted

Accepted 19 June 1980.

*This study was supported by grants from the World Health Organization and the U.S. National Cancer Institute (5P01 CA 06373). relative to the sum of the amounts of estrone (E1) and estradiol (E2) [1-3]. The present study attempts to evaluate further this phenomenon by comparison of some populations that are racially more homogeneous but still show differences in breast cancer risk.

\section{MATERIALS AND METHODS}

\section{Patients}

Study centers were located in four high-risk populations of northern Europe (Denmark, Netherlands, Norway and Sweden) and in two low-risk populations in southern Euròpe (Greece and Yugoslavia). An additional center was in Finland which, although a northern country, has lower reported incidence and mortality from breast cancer than the other Scandinavian countries. The objective in each country was to enroll 40 women 15-18-yr old and 30 age $30-39 \mathrm{yr}$. In the $15-18 \mathrm{yr}$ group, 
Table 1. Source of subjects in the study centers

\begin{tabular}{lll}
\hline Center & Town or area & \multicolumn{1}{c}{ Source } \\
\hline Denmark & Aarhus & $\begin{array}{l}\text { Young: mostly pupils from two schools. } \\
\text { Older: staff of hospital, friends. } \\
\text { Young: students at two high schools. } \\
\text { Older: women attending a population screening } \\
\text { project for cervical cancer. }\end{array}$ \\
Norway & Troms $\phi$ & $\begin{array}{l}\text { Young: students at a vocational school. } \\
\text { Older: women attending a health clinic for } \\
\text { check-up; friends. }\end{array}$ \\
Sweden & Malmö & $\begin{array}{l}\text { Young: high school students. } \\
\text { Older: mostly nurses and friends; a few } \\
\text { healthy patients in a policlinic. }\end{array}$ \\
Finland & Joensuu, & $\begin{array}{l}\text { Young: girls from a secondary school. } \\
\text { Older: from the acquaintances of the study } \\
\text { staff (and their acquaintances). } \\
\text { Young: students at one middle class high school. } \\
\text { Older: mostly women coming to Social Security } \\
\text { clinics for vaccination of children; staff; friends. } \\
\text { Young: students at schools of nursing, } \\
\text { midwifery and medical technology. } \\
\text { Older: staff of several hospitals and } \\
\text { affiliated institutions. }\end{array}$ \\
\hline
\end{tabular}

an attempt was made to have 10 subjects at each single year of age, but this was not achieved in all countries. All the young women were nulliparous and all the older women, were parous. the sources of the subjects are described briefly in Table 1.

The field work was carried out in 1973. Potentially eligible women, very few of whom were unwilling to participate, were interviewed. The following were reasons for exclusion: currently pregnant, pregnancy within the prior 6 months, unusual length of menstrual cycle, history of diabetes, thyroid disorder, cancer, breast lump or cyst, liver disease, uterine curettage (other than for miscarriage), ovarian surgery, pelvic surgery for any neoplasm, current or past systemic endoctrine therapy, oral contraceptive use within the previous 24 months, or current regular use of any medication.

Each eligible woman provided one urine collection during the follicular phase and one during the luteal phase, usually of the same menstrual cycle. In almost all instances, collection of the follicular specimen started on the evening of the 10th day, and of the luteal specimen on the evening of the 21 st day of the cycle, and was completed $12 \mathrm{hr}$ later.

\section{Methods}

After measurement of urine volume and specific gravity, the aliquots, identified only by number, were stored frozen and later shipped frozen to Melbourne. There, estrogens were measured by the modified Brown method [4] and pregnanediol was measured by the method of Cox [5]. For 10\% of urine specimens, a second aliquot was sent under a different code number. Based on these blind duplicates, the coefficients of variation due to replication were $10 \%$ for $\mathrm{E} 1,15 \%$ for $\mathrm{E} 2$, $13 \%$ for $\mathrm{E} 3,4 \%$ for the estriol ratio, and $21 \%$ for pregnanediol. The estrogen profile is described by the estriol ratio, E3/(E1 + E2). This ratio and the concentrations of the individual estrogens and pregnanediol have ap-

Table 2. Average annual age-adjusted breast cancer incidence and mortality rates, per 100,000 female population, in the countries represented in the study

\begin{tabular}{lcccc}
\hline \multirow{2}{*}{ Country } & \multicolumn{2}{c}{ Incidence } & \multicolumn{2}{c}{ Mortality } \\
& Period & Rate & Period & Rate \\
\hline Denmark & $1963-67$ & 68.2 & $1971-75$ & 37.2 \\
Netherlands & $1960-62$ & 62.0 & $1971-75$ & 38.7 \\
Norway & $1968-72$ & 60.8 & $1969-73$ & 25.3 \\
Sweden & $1966-70$ & 72.8 & $1971-75$ & 28.9 \\
Finland & $1966-70$ & 44.9 & $1970-74$ & 21.4 \\
Greece & $1965-67$ & 53.3 & $1970-74$ & 15.0 \\
Yugoslavia & $1968-72$ & 38.2 & $1970-74$ & 14.1 \\
\hline
\end{tabular}

Except as otherwise noted, incidence rates are from Waterhouse et al. [6] and mortality rates from data given in the World Health Statistics Annual, Vol. 1. Incidence data for the Netherlands are from Doll et al. [7] and for Greece from Valaoras et al. [8]. Incidence data for Yugoslavia are for the Province of Slovenia only. Age-adjustment is to the European standard population of Waterhouse $e t$ al. [6]. 
Table 3. Characteristics of the young subjects and of their urine specimens by country and cycle phase

\begin{tabular}{|c|c|c|c|c|c|c|c|}
\hline \multirow[b]{3}{*}{ Characteristic } & \multicolumn{5}{|c|}{ Northern European countries } & \multirow{2}{*}{\multicolumn{2}{|c|}{$\begin{array}{c}\text { Southern European } \\
\text { countries } \\
\text { Low breast } \\
\text { cancer risk }\end{array}$}} \\
\hline & \multicolumn{4}{|c|}{ High breast cancer risk } & \multirow{2}{*}{ Finland } & & \\
\hline & Denmark & Netherlands & Norway & y Sweden & & Greece & Yugoslavia \\
\hline No. of women & 40 & 41 & 39 & 40 & 39 & 46 & 43 \\
\hline Age (range) & $15-18$ & $15-18$ & $15-18$ & $15-18$ & $15-18$ & $15-18$ & $15-18$ \\
\hline Age (mean) & 16.4 & 15.9 & 15.7 & 16.5 & 16.3 & 16.1 & 16.5 \\
\hline Age at menarche & 12.8 & 12.8 & 12.6 & 12.9 & 13.0 & 12.3 & 12.8 \\
\hline \multicolumn{8}{|c|}{ Follicular phase } \\
\hline Urine volume $(\mathrm{ml})$ & 459 & 417 & 446 & $37 \bar{\jmath}$ & 506 & 412 & 310 \\
\hline Urine specific gravity & 1022 & 1022 & 1024 & 1027 & 1023 & 1021 & 1025 \\
\hline Estrone $(\mathrm{E} 1)$ & 7.8 & 7.4 & 6.6 & 8.7 & 7.9 & 7.0 & 10.3 \\
\hline Estradiol $(\mathrm{F}, 2)$ & 3.7 & 3.7 & 3.1 & 4.2 & 3.5 & 4.1 & 5.6 \\
\hline Estriol (E3) & 6.1 & 8.0 & 6.5 & 8.5 & 6.6 & 7.7 & 11.7 \\
\hline Total estrogens & 18.3 & 19.6 & 16.8 & 22.5 & 18.8 & 19.5 & 28.6 \\
\hline Estriol ratio & 0.53 & 0.72 & 0.66 & 0.65 & 0.58 & 0.69 & 0.73 \\
\hline \multicolumn{8}{|c|}{ Luteal phase } \\
\hline Urinc volume $(\mathrm{ml})$ & 427 & 441 & 459 & 405 & 525 & 467 & 365 \\
\hline Urine specific gravity & 1022 & 1022 & 1023 & 1026 & 1023 & 1021 & 1025 \\
\hline Estrone (E1) & 15.7 & 13.9 & 12.0 & 14.7 & 14.2 & 10.8 & 16.4 \\
\hline Estradiol (E2) & 7.3 & 7.0 & 6.1 & 7.6 & 7.1 & 6.4 & 8.4 \\
\hline Estriol (E3) & 18.5 & 17.3 & 14.2 & 18.4 & 13.7 & 16.8 & 23.6 \\
\hline Total estrogens & 43.7 & 39.7 & 33.9 & 42.3 & 36.4 & 35.1 & 50.7 \\
\hline Pregnanediol & 1.4 & 1.0 & 0.8 & 1.3 & 0.7 & 1.2 & 1.7 \\
\hline Estriol ratio & 0.81 & 0.82 & 0.78 & 0.83 & 0.64 & 0.97 & 0.94 \\
\hline
\end{tabular}

Values of estrogen concentrations $(\mu \mathrm{g} / \mathrm{l})$ pregnanediol $(\mathrm{mg} / \mathrm{l})$ and estriol ratios are geometric means. All other values are arithmetic means.

proximately log-normal distributions and so are summarized as geometric means.

\section{RESULTS}

Table 2 shows breast cancer incidence and mortality rates reported in the seven countries represented in the study. In both incidence and mortality the four high-risk countries are clearly differentiated from the two low-risk countries. Finland is also different from the other northern European countries, having incidence rates similar to those of Greece and Yugoslavia and mortality rates intermediate between the two groups. If the data are limited to women under 55 , so as to include generations more similar to the women studied (data not shown), the geographical differences remain - rates are highest in the four northern countries, and Finland occupies an intermediate position.

Data on the study subjects and their urine estrogens are given for the young group in Table 3 and for the older women in Table 4. In view of the equivocal status of Finland with respect to breast cancer risk and of the strikingly different observations for the data from Finland in this study, the data are first cxamined with the Finnish data disregarded.
The means of the estriol ratios for luteal specimens of young women in the four highrisk countries are all lower than those for the two southern low-risk countries. In the follicular specimens of young women, there is only one exception to this same phenomenon, the mean for Netherlands (0.72) being slightly higher than that for Greece (0.69). Among the older women, there are similar trends, but there are two exceptions-Netherlands among the follicular specimens and Denmark among the luteal. Altogether, of 16 possible comparisons of the ratio in a high-risk area with that in the lowest of the low-risk areas, the ratio is in the expected direction (lower in the high-risk area) in 13 and in 3 it is not. There is no instance of the contrary-that is, a higher ratio in a high-risk area than in both of the southern low-risk areas. Data combined for the high-risk and low-risk areas are shown in Table 5. The directions of differences in the estriol ratios are the same in all four possible comparisons and are significantly so $(P<0.05)$ in two (follicular specimens in older women and luteal specimens in the younger group).

It is of interest that, in all comparisons except that for the luteal specimens of young women, the higher estriol ratios in the southern low-risk countries occur in spite of the 
Table 4. Characteristics of the older subjects and of their urine specimens by country and cycle phase

\begin{tabular}{|c|c|c|c|c|c|c|c|}
\hline \multirow[b]{3}{*}{ Characteristic } & \multicolumn{5}{|c|}{ Northern European countries } & \multirow{2}{*}{\multicolumn{2}{|c|}{$\begin{array}{c}\text { Southern European } \\
\text { countries } \\
\text { Low breast } \\
\text { cancer risk }\end{array}$}} \\
\hline & \multicolumn{4}{|c|}{ High breast cancer risk } & \multirow{2}{*}{ Finland } & & \\
\hline & Denmark & Netherlands & Norway & y Sweden & & Greece & Yugoslavia \\
\hline No. of women & 30 & 33 & 30 & 30 & 32 & 30 & 31 \\
\hline Age (range) & $30-39$ & $30-39$ & $30-39$ & $30-39$ & $30-39$ & $30-39$ & $30-39$ \\
\hline Age (mean) & 34.6 & 35.7 & 35,1 & 33.5 & 34.3 & 34.9 & 34.2 \\
\hline Age at menarche & 13.1 & 13.1 & 13.1 & 13.6 & 13.9 & 12.8 & 14.0 \\
\hline \multicolumn{8}{|c|}{ Follicular phase } \\
\hline Urine volume $(\mathrm{ml})$ & 572 & 539 & 613 & $505^{\circ}$ & 522 & 569 & 466 \\
\hline Urine specific gravity & 1019 & 1020 & 1021 & 1022 & 1023 & 1019 & 1023 \\
\hline Estrone $(\mathrm{E} 1)$ & 12.3 & 14.0 & 14.0 & 13.0 & 17.4 & 16.0 & 15.6 \\
\hline Estradiol (E\&) & 6.3 & 6.9 & 7.3 & 6.9 & 8.0 & 8.2 & 9.0 \\
\hline Estriol (E3) & 13.0 & 16.3 & 13.2 & 11.7 & 12.0 & 23.9 & 18.8 \\
\hline Total estrogens & 32.8 & 38.9 & 36.1 & 33.0 & 39.2 & 49.7 & 45.6 \\
\hline Estriol ratio & 0.70 & 0.78 & 0.62 & 0.59 & 0.47 & 0.98 & 0.76 \\
\hline \multicolumn{8}{|c|}{ Luteal phase } \\
\hline Urine volume $(\mathrm{ml})$ & 571 & 599 & 675 & 550 & 603 & 644 & 487 \\
\hline Urine specific gravity & 1019 & 1019 & 1022 & 1020 & 1025 & 1019 & 1021 \\
\hline Estrone $(\mathrm{E} 1)$ & 13.2 & 11.6 & 14.2 & 13.4 & 15.8 & 14.2 & 17.9 \\
\hline Estradiol (E2) & 6.2 & 5.8 & 6.9 & 7.0 & 7.2 & 6.9 & 9.7 \\
\hline Estriol (E3) & 20.5 & 16.8 & 17.9 & 15.8 & 15.6 & 22.9 & 27.9 \\
\hline Total estrogens & 41.4 & 36.2 & 40.9 & 38.3 & 40.2 & 45.7 & 58.3 \\
\hline Pregnanediol & 2.6 & 2.2 & 3.4 & 2.6 & 2.6 & 2.6 & 2.9 \\
\hline Estriol ratio & 1.05 & 0.96 & 0.84 & 0.77 & 0.67 & 1.08 & 1.00 \\
\hline
\end{tabular}

See footnotes to Table 3.

Table 5. Characteristics of the urine specimens of the study subjects in four high risk countries and two low risk countries, by age group and cycle phase

\begin{tabular}{lcccc}
\hline & \multicolumn{2}{c}{ Young women } & \multicolumn{2}{c}{ Older women } \\
\cline { 2 - 5 } & $\begin{array}{l}\text { High risk } \\
\text { northern }\end{array}$ & $\begin{array}{c}\text { Low risk } \\
\text { southern } \\
\text { countries }\end{array}$ & $\begin{array}{c}\text { High risk } \\
\text { northern } \\
\text { countries }\end{array}$ & $\begin{array}{c}\text { Low risk } \\
\text { southern } \\
\text { countries }\end{array}$ \\
\hline Characteristic & 160 & 89 & 123 & 61 \\
\hline No. of women & \multicolumn{2}{c}{ Follicular phase } & & \\
Estrone (E1) & 7.6 & 8.5 & 13.3 & 15.8 \\
Estradiol (E2) & $(6.8-8.5)$ & $(7.4-9.7)$ & $(11.6-15.3)$ & $13.4-18.5)$ \\
& 3.7 & 4.8 & 6.8 & 8.6 \\
Estriol (E3) & $(3.3-4.1)$ & $(4.2-5.4)$ & $(6.0-7.9)$ & $(7.3-10.1)$ \\
Total estrogens & 7.2 & 9.4 & 13.5 & 21.1 \\
Estriol ratio & $(6.3-8.2)$ & $(8.1-11.0)$ & $(11.4-16.2)$ & $(17.6-25.4)$ \\
& 19.2 & 23.5 & 35.2 & 47.6 \\
Estrone (E1) & $(17.2-21.4)$ & $(20.6-26.9)$ & $(30.6-40.7)$ & $(40.9-55.5)$ \\
& 0.64 & 0.71 & 0.67 & 0.86 \\
Estradiol (E2) & $(0.58-0.70)$ & $(0.64-0.79)$ & $(0.60-0.74)$ & $(0.74-1.00)$ \\
& 14.0 & Luteal phase & & \\
Estriol (E3) & $(12.6-15.5)$ & $(11.4-15.3)$ & $(11.7-14.6)$ & $(13.5-19.0)$ \\
Total estrogens & 7.0 & 7.3 & 6.5 & 8.2 \\
Pregnanediol & $(6.3-7.7)$ & $(6.4-8.3)$ & $(5.8-7.2)$ & $(6.9-9.7)$ \\
Estriol ratio & 17.0 & 19.8 & 17.6 & 25.3 \\
& $(15.1-19.3)$ & $(17.0-23.0)$ & $(15.3-20.2)$ & $(21.3-30.5)$ \\
& 39.7 & 41.9 & 39.1 & 51.7 \\
& $(36.0-44.1)$ & $(36.6-47.9)$ & $(35.2-43.5)$ & $(44.6-60.4)$ \\
& 1.1 & 1.4 & 2.7 & 2.8 \\
& $(1.0-1.3)$ & $(1.1-1.8)$ & $(2.3-3.1)$ & $(2.3-3.3)$ \\
& 0.81 & 0.96 & 0.90 & 1.04 \\
& $(0.74-0.89)$ & $(0.85-1.08)$ & $(0.80-1.01)$ & $(0.90-1.21)$ \\
\hline
\end{tabular}

See footnotes to Table 3.

Values given in parentheses are $95 \%$ confidence limits. 
fact that concentrations of E1 and E2 are higher than in the high-risk areas--that is, the concentrations of all three estrogens are higher but that of E3 is especially so. In the luteal specimens of young women the pattern is not so clear but it appears that, on average, the concentrations of E1 and E2 are at least not lower than those in the high-risk areas.

Among the four high-risk areas there is no clear pattern except for a tendency for the ratios to be high in the Netherlands, and, in the older women, in Denmark. There is no consistency to the direction of the difference between estriol ratios in the two southern lowrisk areas.

In contrast to the results of the comparison of the high-risk with the southern low-risk areas, the data for Finland do not support the estriol ratio hypothesis. On the basis of the relatively low breast cancer incidence in Finland it would be predicted from the hypothesis that estriol ratios would be high in that center. Instead, the ratio in Finland is lower than that of any of the high-risk areas. The pregnanediol concentration is also low in many young women in Finland as reflected in the low mean value, suggesting a high frequency of anovular menstrual cycles. However, frequency of anovulation varies strikingly with age in this age-group and examination of this question will require more detailed analysis.

\section{DISCUSSION}

This comparison of high breast cancer risk northern European countries with low-risk countries in southern Europe provides data supportive of the hypothesis that a population's breast cancer risk is inversely associated with the urine estriol ratios of its young women [9]. The fact that the differences in estriol ratio between high-risk and low-risk areas are less than those previously seen in comparisons of Asian and North American populations [1] is consistent with the fact that the differences in breast cancer rates are less. Some exceptions to the overall pattern are to be expected even if the hypothesis is correct-the variable under study has a wide range of values and the individual study groups are relatively small. Further, no special effort was made in this study to select subjects in terms of demographic variables, such as socio-economic status, which is associated with considerable variation in the estriol ratio within a population [10].

In contrast, the comparison of data from Finland with those from other Scandinavian and northern countries is inconsistent. The inconsistency is even more remarkable when it is considered that a special effort was made to obtain the Finnish specimens from a rural area in Northern Karelia where it was judged that the factors responsible for the rapidly increasing breast cancer rates in Finland [11] would be least influential. The contrast between the expectation and the observation in the Finnish data is so strong as to suggest that there is some circumstance in Finland which is unusual and an understanding of which might be important to the elucidation of breast cancer etiology.

Acknowledgements - $W e$ are indebted to the many staff members who carried out the extensive field work required for the investigation.

\section{REFERENGES}

1. B. Macmahon, P. Cole, J. B. Brown, K. Aoki, T. M. Lin, R. W. Morgan and N. Woo, Urine oestrogen profiles of Asian and North American women. Int. 7. Cancer 14, 161 (1974).

2. L. E. Dickinson, B. Macmahon, P. Cole and J. B. Brown, Estrogen profiles of Oriental and Caucasian women in Hawaii. New Engl. 7. Med. 291, 1211 (1974).

3. J. Gross, B. Modan, B. Bertini, O. Spira, F. deWaArd, J. H. H. Thijssen and P. Vestergaard, Relationship between steroid excretion patterns and breast cancer incidence in Israeli women of various origins. 7. nat. Cancer Inst. 59, 7 (1977).

4. J. B. BRown, Unpublished (1979).

5. R. I. Cox, Gas chromatography in the analysis of urinary pregnanediol. 7 . Chromatogr. 12, 242 (1963).

6. J. Waterhouse, C. Mutr, P. Correa and J. Powell, Cancer Incidence in Five Continents. Volume III-1976. I.A.R.C. Scientific Publications No. 15. International Agency for Research on Cancer, Lyon (1976). 
7. R. Doll, P. Payne and J. Waterhouse, Cancer Incidence in Five Continents. A Technical Report. Springer-Verlag, New York (1966).

8. V. G. Valaoras, B. Macmahon, D. Trichopoulos and A. Polyahronopoulou, Lactation and reproductive histories of breast cancer patients in Greater Athens, Greece, 1965-67. Int. J. Cancer 4, 350 (1969).

9. P. Cole and B. MacMahon, Oestrogen fractions during early reproductive life in the aetiology of breast cancer. Lancet i, 604 (1969).

10. D. Trichopoulos, B. MacMahon and J. B. Brown, Socio-economic status, urine estrogens and breast cancer risk. J. nat. Cancer Inst. 64, 753 (1980).

11. L. Teppo, M. Hakama, T. Hakulinen, M. Lehtonen and E. Saxén, Cancer in Finland 1953-1970: Incidence, Mortality, Prevalence. Acta Path. Microbiol. Scand., Section A 1975, Supplement No. 252. Munksgaard, Copenhagen (1975). 